\title{
Domains and Facets: Hierarchical Personality Assessment Using the Revised NEO Personality Inventory
}

\author{
Paul T. Costa, Jr. and Robert R. McCrae \\ Gerontology Research Center \\ National Institute on Aging, $\mathrm{NIH}$ \\ Baltimore, $M D$
}

\begin{abstract}
Personality traits are organized hierarchically, with narrow, specific traits combining to define broad, global factors. The Revised NEO Personality Inventory (NEO-PI-R; Costa \& McCrae, 1992c) assesses personality at both levels, with six specific facet scales in each of five broad domains. This article describes conceptual issues in specifying facets of a domain and reports evidence on the validity of NEO-PI-R facet scales. Facet analysis-the interpretation of a scale in terms of the specific facets with which it correlates--is illustrated using alternative measures of the five-factor model and occupational scales. Finally, the hierarchical interpretation of personality profiles is discussed. Interpretation on the domain level yields a rapid understanding of the individual; interpretation of specific facet scales gives a more detailed assessment.
\end{abstract}

The Revised NEO Personality Inventory (NEO-PI-R; Costa \& McCrae, $1992 \mathrm{c}$ ) is a 240 -item questionnaire designed to operationalize the five-factor model of personality (FFM; Digman, 1990; McCrae \& John, 1992). Over the past decade, the FFM has become a dominant paradigm in personality psychology, yet most attention has been focused on the Big Five factors themselves, to the neglect of the specific traits that define these factors. In this article we emphasize the facet scales of the NEO-PI-R, discussing the logic behind their development, the evidence of their discriminant validity, and their utility in interpreting the nature of other personality scales. We also address the complexities of interpreting profiles from an instrument that provides both a global and a detailed assessment of an individual's personality. The first part of the article may appeal chiefly to the personality theorist, 
the middle part to the researcher, and the last to the clinician interested in the assessment of individuals.

\section{A HIERARCHICAL MODEL OF PERSONALITY STRUCTURE}

In an article on the cross-cultural invariance of personality structure, Paunonen, Jackson, Trzebinski, and Forsterling (1992) concluded that "If one desires a broad overview of personality dimensions, we regard the five-factor model as most promising, but if one's theoretical or pragmatic requirements are for a more differentiated, detailed perspective, perhaps other measurement models should be considered" (p. 455). The same sentiment has been expressed by many others (Briggs, 1989; Buss, 1989; Mershon \& Gorsuch, 1988), all of whom noted the greater precision of measurement, if narrower focus, of more specific traits.

What these critics of the FFM have failed to do, however, is to agree upon which specific traits should be measured. Many alternative sets of primary traits have been proposed, from the 16 factors of Cattell to the 20 Murray needs measured by Jackson's (1984) Personality Research Form. Although most of these scales can be interpreted in terms of the FFM, they were constructed without reference to it and do not represent a systematic carving up of the five-factor space. In this article we describe an approach to the assessment of traits at both general and specific levels explicitly guided by the FFM: The domain-and-facet approach of the NEO-PI-R.

\section{The Logic of Domains and Facets}

As Goldberg (1993) noted, there is a long tradition of identifying different levels of specificity in personality trait assessment. Conceptually, this is usually illustrated by the combination of discrete behaviors to form specific traits, and the combination of groups of covarying traits to form broad dimensions of personality. Factor analysts such as Guilford, Cattell, and Eysenck all adopted such a hierarchical model, although Guilford and Cattell emphasized the lower level traits and Eysenck the higher. In the usual factor analytic approach, test items were factored, usually using oblique rotations, and the obtained factor scores were then factored themselves to yield second order factors. Third order factors were occasionally reported.

In practice, this bottom-up scheme presented several difficulties. Most important was the specification of the initial pool of items. What should be included? Even large item pools may omit important aspects of personality. For example, McCrae, Costa, and Piedmont (1993) reported that there are relatively few items in the California Psychological Inventory that measure Agreeableness, and J. H. Johnson, Butcher, Null, and K. N. Johnson's (1984) 
item factor analysis of the Minnesota Multiphasic Personality Inventory (Hathaway \& McKinley, 1983) found no factors related to Conscientiousness.

The lexical approach, in which the body of trait names in the natural language has been adopted as an exhaustive enumeration of traits, has proven to be the most fruitful guide to a comprehensive model of personality; it was in analyses based on trait terms that the FFM was first discovered. But the lexical approach has distinct limitations as the basis of a hierarchical model of personality, first because some specific traits are not well represented in the natural language (McCrae, 1990), and second because trait terms are found at every level of breadth (John, Hampson, \& Goldberg, 1991), from extremely narrow (e.g., sanctimonious, sedentary, sirupy) to extremely broad (e.g., kind, weak, able). Broad terms naturally covary with many narrower terms, whereas narrower terms may not covary with each other. The result is that when representative lists of trait adjectives are factored, the broader terms account for the lion's share of the covariance, and only five broad factors typically emerge (Goldberg, 1990).

These problems are minimized by a top-down approach to hierarchical assessment. In the program of research that lead to the development of the NEO-PI-R, we began by looking for the broadest and most pervasive themes that recurred in personality measures. Eysenck's Extraversion (E) and Neuroticism (N) had already been identified as the Big Two by Wiggins (1968), and we proposed that Openness to Experience $(\mathrm{O})$ also qualified as a major dimension of personality (Costa \& McCrae, 1978). A few years later we recognized the need for Agreeableness (A) and Conscientiousness (C).

Rather than use the term factors, which might apply to any level in the hierarchy, we chose to call N, E, O, A, and C domains, a term defined as "a sphere of concern or function" (Morris, 1976, p. 389). Intellectual curiosity, need for variety, and aesthetic sensitivity all concerned some aspect of experiencing the world, and thus belonged in the domain of $O$. Although this terminology is somewhat unusual, it is not unparalleled: About the same time, and quite independently, Digman (1979) presented a paper entitled "The Five Major Domains of Personality Variables: Analyses of Personality Questionnaire Data in the Light of the Five Robust Factors Emerging from Studies of Rated Characteristics."

We regarded domains as multifaceted collections of specific cognitive, affective, and behavioral tendencies that might be grouped in many different ways, and we used the term facet to designate the lower level traits corresponding to these groupings. ${ }^{1}$ Our working metaphor was the mathematical set, which could be divided into subsets by selecting different combinations of elements.

\footnotetext{
${ }^{1}$ This usage should be distinguished from that of Guttman (1954), who used the term facet to refer to one of several conceptual factors that, when crossed, yielded a set of variables. A well-known example is Guilford's (1967) structure of intellect model, which uses Operation, Content, and Product as facets in Guttman's sense.
} 


\section{Guidelines for Faceting Domains}

Consider the set of attributes that together define the domain of $\mathrm{N}$, such as chronic tendencies to feel tense, worried, irritable. There are many possible ways to group these attributes into what we might consider specific traits (see Figure 1). We could treat them singly, recognizing for example the difference between tension and apprehension, as Spielberger (1972) did; or we might combine these two with other traits like shy and guilt-prone to form a broader anxiety cluster that might be contrasted with depression and hostility clusters, as Zuckerman and Lubin (1965) suggested.

Hofstee, De Raad, and Goldberg (1992), noting that many traits in the lexicon have appreciable loadings on two of the five basic factors, have suggested that facets can be identified by their location on the ten circumplexes formed by pairs of the five factors. Traits such as irritable and touchy, which are primarily located in the domain of $\mathrm{N}$, might be grouped together because they share a secondary loading on low A.

Each of these ways of identifying specific traits within the domain of $\mathrm{N}$ is reasonable, but the differences among them explain why there is so little consensus on lower level traits (Briggs, 1989). In fact, with only twelve elements in a set, there are 4,094 different proper, non-null subsets. The ways in which a domain as broad as $\mathrm{N}$ could be subdivided is virtually limitless.

This is not to say that the identification of specific facets is not useful. Even if there is an element of arbitrariness in the way in which a domain is subdivided, there are still good reasons to make distinctions. Any meaning-

LESS MEANINGFUL

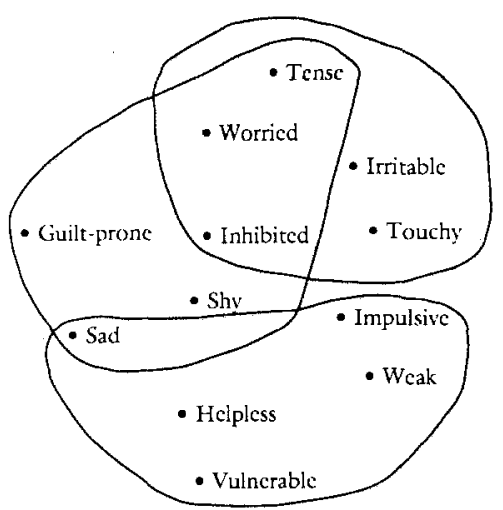

MORE MEANINGFUL

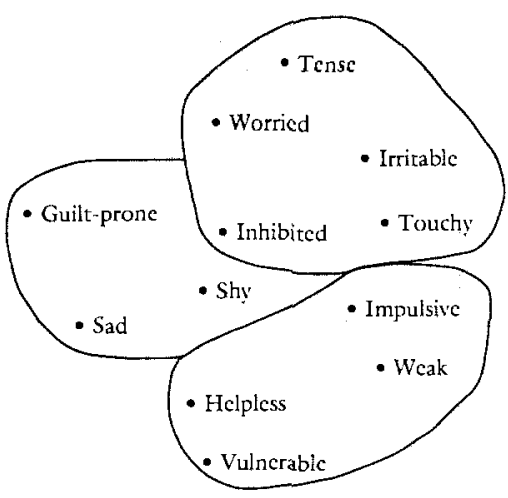

FIGURE 1 An illustration of how traits in the domain of Neuroticism might be grouped into facets. Overlapping groupings are less meaningful than mutually exclusive groupings. 
ful specification of facets should provide more information than the undifferentiated global domain scale, and some specifications are more meaningful than others.

Perhaps most obviously, facets should represent the more closely covarying elements within the domain, not arbitrary combinations of elements; and they should be mutually exclusive, with each element in the domain assigned to only a single facet, as shown in Figure 1. Both these goals are facilitated by factor analyses of items within the domain, because factor analysis identifies discrete clusters of covarying items. This kind of item factor analysis was one of the steps in the development of NEO-PI-R facets (Costa, McCrae, \& Dye, 1991).

Ideally, all facets should be of comparable scope and breadth in content. It would make little sense to insist upon fine distinctions in some aspects of personality while allowing only coarse distinctions elsewhere. Narrower facets are desirable insofar as they measure specific traits with great fidelity, but if the full domain is to be covered, the number of narrow facets needed might become unmanageable.

Exhausting the domain would seem to be desirable: Just as the FFM is intended to be a comprehensive taxonomy of all personality traits, so each set of facets might aspire to be a comprehensive specification of the contents of a domain. But this requirement can be problematic. For example, hypochondriasis has been regarded as a facet of N (Eysenck \& Wilson, 1976), but we deliberately omitted somatic complaints from the NEO-PI-R because we wanted an uncontaminated measure of $\mathrm{N}$ to predict health complaints. It is sometimes difficult to know the boundary between a domain of personality and its external correlates.

Finally, the facets of each domain should be as consistent as possible with existing psychological constructs. It is in combing the literature that we identify traits relevant to each domain, and, where empirically supportable, it makes sense to retain these initial constructs. They are familiar to personality psychologists, and their previous use suggests that they will have sorne utility. The NEO-PI-R N facets of Anxiety, Angry Hostility, Depression, Self-Consciousness, Impulsiveness, and Vulnerability all have clear roots in the psychological literature (Costa \& McCrae, 1980).

\section{A Complication: Overlapping Domains}

The elegance of a purely hierarchical model of personality structure is marred by the fact that the domains themselves are not mutually exclusive. That is to say, there are traits that appear to lie within two or more domains. In the language of factor analysis, personality cannot be adequately described by simple structure; some traits load on more than one factor.

This phenomenon is most clearly illustrated by the Interpersonal Circumplex (Leary, 1957; Wiggins, 1979), a circular arrangement of traits 
around two orthogonal axes. By emphasizing the measurement of traits at each point on the perimeter of the circle, circumplex theorists make a virtue of what simple-structure theorists regard as an embarrassment. The traditional axes of the circumplex are Love and Dominance, but empirical studies show that $E$ and $A$ are equally plausible alternative axes, with $E$ located between Dominance and Love, and A between Love and Submission (McCrae \& Costa, 1989).

Hofstee and colleagues (1992) have built upon this finding to suggest a new structure composed of the ten circumplexes defined by all possible pairs of the five factors. In this Abridged Big Five Dimensional Circumplex (AB5C) model, facets correspond to segments of the circumplex. NEO-PI-R Activity might be considered a facet in this approach, because it is related to both $\mathrm{E}$ and $\mathrm{C}$.

Although this is an appealingly systematic approach to the specification of facets, it does not seem to us to be optimal for two reasons. First, it violates the canon that facets should be of comparable breadth. At least when applied to English-language trait terms, many of the segments appear to be empty, or at least to contain few traits, whereas others are very broad. Figure 1 in Hofstee and colleagues (1992) lists 43 terms that combine low A with high $\mathbf{N}$ (or vice versa), but only 13 that combine low A with low $\mathbf{N}$ or high $A$ with high $\mathbf{N}$.

Second, and more crucially, this system fails to make distinctions among substantively different traits that have the same location in the circumplex model. NEO-PI-R Gregariousness and Positive Emotions are both relatively pure markers of $\mathrm{E}$, and they would be assigned to the same facet by the AB5C approach. Yet they refer to entirely different sets of behaviors (preferences for interpersonal interactions vs. characteristic levels of happiness or joy), and they are in fact only modestly correlated, $r=.35$ (Costa \& McCrae, 1992c). Surely they merit separate measurement.

The lack of simple structure in the real world of personality traits complicates hierarchical models. We chose to include traits such as Activity and Altruism in the NEO-PI-R despite their multiple loadings because we believed they were important aspects of personality that should be measured. To accommodate needs for simplicity, we assign each facet to one and only one domain and calculate raw domain scores by summing the facets. To increase precision, we provide formulas for estimating factor scores that take into account information from all facets. The computer Interpretive Report automatically calculates these factor scores as the basis of the interpretation.

\section{FACET SCALES IN THE NEO-PI-R}

We measure each domain as the sum of six facet scales. Unlike five and seven, there is nothing magical about the number six. It was chosen because we saw the need to make at least that many distinctions within domains and 
because inclusion of more than six would soon lead to intellectual overload. There is one other reason: In the late 1970s we spent a good deal of time reading about factor analysis, and Gorsuch (1974) warned that "it is generally difficult to replicate factors with fewer than five or six salient variables per factor" (p. 295). We naturally wanted a replicable structure, and by following Gorsuch's advice, it appears that we have obtained one.

We recently conducted a study in which we gathered NEO-PI-R data from over 1,500 employees of a large national organization (Costa et al., 1991). Because of the size and diversity of this sample, it was ideal for testing the robustness of the NEO-PI-R factor structure. Separate analyses were conducted for men and women, younger (age 21 to 29) and older (age 30 to 65 ) individuals, and White and non-White subjects. In each case, a similar structure was found, with all facets showing a substantial loading on their intended factor. With minor variations, this structure has been replicated in college students (Costa \& McCrae, in press), in older adults tested by computer administration (Costa \& McCrae, 1992b), and in spouse and peer ratings on the observer rating form of the NEO-PI-R (Costa \& McCrae, 1992d; McCrae, 1991).

The facets within each domain cohere so well in factor analyses that one might wonder whether they are not simply interchangeable markers of the factor. This is a crucial question for hierarchical models, because the specific traits that form the lower level of the hierarchy must show evidence of specific variance not shared with other variables. Without specific variance, there would be no need to measure separate facets, and they could not provide the incremental predictive validity that critics of global dimensions postulate. There are several ways to demonstrate that NEO-PI-R scales contain valid specific variance.

Factor analysts distinguish between common variance, which is shared among the variables in an analysis, and specific variance, which is non-error variance unique to a particular variable (Gorsuch, 1974). Specificity is estimated by subtracting communality from reliability, and the loading of each variable on its specific factor is the square root of its specificity. Table 1 presents a factor analysis of NEO-PI-R facets showing both their common and their specific factor loadings. (The last column in the Table is not a single factor, but the loadings of each variable on its own specific factor.) This is a principal factors analysis rather than the principal components analysis we normally report, because the specificity analysis assumes a common factor model. Note that all facets load on the intended common factor, but that, in addition, all show modest to substantial loadings on their own specific factor. Indeed, seven of the variables show their highest loading on the specific factor, notably Openness to Values. The attitudinal component of this facet has often been noted (e.g., John, 1989).

From an external perspective, the differentiation of facets within a domain is a matter of discriminant validity. We have addressed that issue in a series of analyses, examining questionnaire scale (Costa \& McCrae, 1992d) 
TABLE 1

Common and Specific Factor Loadings for NEO-PI-R Facet Scales

\begin{tabular}{|c|c|c|c|c|c|c|}
\hline \multirow{2}{*}{$\begin{array}{l}\text { NEO-PI-R } \\
\text { Facet Scale }\end{array}$} & \multicolumn{5}{|c|}{ Common Factor } & \multirow[b]{2}{*}{$s$} \\
\hline & $N$ & $E$ & $O$ & $A$ & $C$ & \\
\hline N1: Anxiety & .77 & -.04 & -.01 & .00 & -.10 & .41 \\
\hline N2: Angry Hostility & .64 & -.12 & .00 & -.45 & -.09 & .34 \\
\hline N3: Depression & .78 & -.17 & .01 & -.02 & -.26 & .33 \\
\hline N4: Self-Consciousness & .67 & -.24 & -.07 & .07 & -.21 & .36 \\
\hline N5: Impulsiveness & .49 & .20 & .11 & -.17 & -.34 & .51 \\
\hline N6: Vulnerability & .68 & -.16 & -.13 & -.04 & -.40 & .33 \\
\hline E1: Warmth & -.09 & .72 & .14 & .29 & .15 & .29 \\
\hline E2: Gregariousness & -.15 & .61 & .03 & .01 & .04 & .57 \\
\hline E3: Assertiveness & -.30 & .45 & .15 & -.30 & .38 & .46 \\
\hline E4: Activity & -.05 & .47 & .18 & -.17 & .44 & .40 \\
\hline E5: Excitement Seeking & .00 & .49 & .25 & -.31 & -.06 & .50 \\
\hline E6: Positive Emotions & -.08 & .68 & .25 & .15 & .11 & .41 \\
\hline O1: Fantasy & .19 & .15 & .54 & -.14 & -.28 & .56 \\
\hline O2: Aesthetics & .08 & .05 & .69 & .11 & .08 & .51 \\
\hline O3: Feelings & .35 & .34 & .49 & -.01 & .09 & .42 \\
\hline O4: Actions & -.20 & .22 & .51 & .02 & .04 & .48 \\
\hline O5: Ideas & -.17 & -.02 & .69 & -.07 & .15 & .51 \\
\hline O6: Values & -.04 & .12 & .42 & -.04 & -.11 & .68 \\
\hline A1: Trust & -.27 & .33 & .12 & .44 & .08 & .62 \\
\hline A2: Straightforwardness & -.03 & -.06 & -.08 & .63 & .18 & .52 \\
\hline A3: Altruism & -.06 & .46 & .02 & .57 & .26 & .39 \\
\hline A4: Compliance & -.18 & .00 & -.06 & .69 & .01 & .28 \\
\hline A5: Modesty & .12 & -.18 & -.07 & .50 & -.11 & .60 \\
\hline A6: Tender-Mindedness & -.01 & .18 & .10 & .52 & .09 & .48 \\
\hline $\mathrm{C1}$ : Competence & -.37 & .22 & .14 & .09 & .60 & .32 \\
\hline $\mathrm{C} 2:$ Order & -.02 & .07 & -.14 & .03 & .59 & .53 \\
\hline C3: Dutifulness & -.21 & .03 & -.02 & .24 & .63 & .34 \\
\hline C4: Achievement Striving & -.13 & .19 & .15 & -.07 & .72 & .27 \\
\hline C5: Self-Discipline & -.33 & .15 & .01 & .12 & .73 & .27 \\
\hline C6: Deliberation & -.31 & -.16 & -.11 & .22 & $\mathbf{5 3}$ & .49 \\
\hline
\end{tabular}

Note. These are varimax-rotated principal factors with iterated communalities. NEO-PI-R = Revised NEO Personality Inventory; $\mathbf{N}=$ Neuroticism; $\mathbf{E}=$ Extraversion; $\mathrm{O}=$ Openness to Experience; $\mathrm{A}=$ Agreeableness; $\mathrm{C}=$ Conscientiousness; $s=$ square root of the facet's specificity, which is estimated by coefficient alpha minus communality. Data adapted from Costa, McCrae, and Dye (1991); $N=1,539$. Loadings $\geq \pm .40$ are given in boldface.

and adjective (McCrae \& Costa, 1992) correlates of individual facets. Data from an analysis of the California Q-Set (CQS; Block, 1961) provide additional evidence.

Since 1981, the CQS has been administered to participants in the Baltimore Longitudinal Study of Aging (BLSA; Shock et al., 1984), using the self-sort procedure of Bem and Funder (1978). An earlier report (McCrae, 
Costa, \& Busch, 1986) showed links between the CQS and the five factors. We now report data on facet correlates from an independent sample of 220 men and 160 women, aged 19 to 96 , who completed the NEO-PI-R by computer administration between 1989 and 1992. Most of these completed the CQS on the same visit to the Gerontology Research Center; the rest completed it within 4 years of taking the NEO-PI-R. We identified the five largest CQS correlates for each of the 30 NEO-PI-R facets; they are summarized in Table 2 .

All of these correlates (and many more not reported in the Table) are statistically significant, and a quick examination of item content shows clear convergent validity for most of the facets: The strongest CQS correlate of NEO-PI-R Gregariousness is "Emphasizes being with others; gregarious"; the strongest correlate of Aesthetics is "Enjoys esthetic impressions; is esthetically reactive." But is there also discriminant validity? Do the facets in the same domain show a distinctive pattern of correlates that differentiates them from each other?

To test this, we adopted an approach earlier used in analyses of adjective correlates (McCrae \& Costa, 1992). Two judges (a psychologist and psychology graduate student), blind to the results in Table 2 , were each given a deck of 30 cards in random order, on each of which were printed the five CQS correlates of one of the NEO-PI-R scales, together with the observed correlation. The judges' task was to identify each facet from its correlates.

This is a rigorous test of discriminant validity, because it is limited by the availability of discriminating content in the CQS and by the skill and knowledge of the judges as well as by the discriminant validity of NEO-PI-R scales. Yet as the footnotes to Table 2 show, both judges were correct in their judgments in the great majority of instances: The first judge correctly identified $28(93 \%)$ of the facets from their correlates; the second judge identified $26(87 \%)$ of the facets. Each facet was correctly identified by at least one of the judges. These results strongly support the discriminant validity of NEO-PI-R facet scales. ${ }^{2}$

A careful examination of Table 2 reveals a good deal about the individual facets beyond such obvious associations as "Is basically anxious" with NEO-PI-R Anxiety. For example, none of the item content in the Excitement Seeking scale concerns sexual interest, but two of its strongest CQS correlates do. Sex, it appears, is exciting. Again, it might seem puzzling that

\footnotetext{
${ }^{2}$ In fact, judges worked from results of a preliminary analysis, before it was discovered that 6 of the 386 subjects had reversed the most and least characteristic ends of the sort. Eliminating these 6 subjects made only small changes in most of the correlates (131 of the 150 preliminary correlates are among the final correlates presented in Table 2), but the changes were usually in the direction of stronger and more meaningful results. For example, the correlation between $\mathrm{C} 3$ : Dutifulness and "Genuinely dependable, responsible" increased from .28 to .39 . Judgments based on the final analyses presented in Table 2 might have shown even stronger confirmation of convergent and discriminant validity.
} 
TABLE 2

California Q-Set Correlates of NEO-PI-R Facet Scales

\begin{tabular}{|c|c|c|}
\hline NEO-PI-R Facet Scale & $\mathbf{r}$ & CQS Item \\
\hline N1: Anxiety ${ }^{a, b}$ & $\begin{array}{r}.51 \\
-.38 \\
-.38 \\
.35 \\
-.34\end{array}$ & $\begin{array}{l}\text { 68. Basically anxious } \\
\text { 74. Satisfied with self } \\
\text { 75. Clearcut, consistent personality } \\
\text { 40. Vulnerable to threat, generally fearful } \\
\text { 33. Calm, relaxed in manner }\end{array}$ \\
\hline N2: Angry Hostility ${ }^{\mathrm{a}, \mathrm{b}}$ & $\begin{array}{r}-.42 \\
.41 \\
-.40 \\
.38 \\
-.35\end{array}$ & $\begin{array}{l}\text { 33. Calm, relaxed in manner } \\
\text { 34. Overreactive to frustration, irritable } \\
\text { 75. Clearcut, consistent personality } \\
\text { 38. Has hostility toward others } \\
\text { 84. Is cheerful }\end{array}$ \\
\hline N3: Depression ${ }^{\mathrm{a}, \mathrm{b}}$ & $\begin{array}{r}-.43 \\
.41 \\
.40 \\
.39 \\
.38\end{array}$ & $\begin{array}{l}\text { 74. Satisfied with self } \\
\text { 47. Tends to feel guilty } \\
\text { 78. Feels cheated, victimized by life } \\
\text { 72. Concerned with own adequacy } \\
\text { 82. Fluctuating moods }\end{array}$ \\
\hline N4: Self-Consciousness ${ }^{\mathrm{a}, \mathrm{b}}$ & $\begin{array}{r}.39 \\
.38 \\
-.36 \\
.35 \\
-.35\end{array}$ & $\begin{array}{l}\text { 72. Concerned with own adequacy } \\
\text { 13. Thin-skinned, sensitive to slights } \\
\text { 92. Has social poise } \\
\text { 47. Tends to feel guilty } \\
\text { 74. Satisfied with self }\end{array}$ \\
\hline N5: Impulsiveness ${ }^{\mathrm{a}, \mathrm{b}}$ & $\begin{array}{r}-.32 \\
-.26 \\
.24 \\
.23 \\
-.22\end{array}$ & $\begin{array}{l}\text { 75. Clearcut, consistent personality } \\
\text { 33. Calm, relaxed in manner } \\
\text { 46. Engages in fantasy and daydreams } \\
\text { 67. Self-indulgent } \\
\text { 70. Behaves in ethically consistent manner }\end{array}$ \\
\hline N6: Vulnerability ${ }^{\mathbf{a}, \mathrm{b}}$ & $\begin{array}{r}.37 \\
.35 \\
-.34 \\
.31 \\
.30\end{array}$ & $\begin{array}{l}\text { 72. Concerned with own adequacy } \\
\text { 68. Basically anxious } \\
\text { 52. Behaves in assertive fashion } \\
\text { 45. Brittle ego-defenses } \\
\text { 30. Gives up in face of frustration }\end{array}$ \\
\hline E1: Warmth ${ }^{a, b}$ & $\begin{array}{r}-.50 \\
.48 \\
.45 \\
.42 \\
.41\end{array}$ & $\begin{array}{l}\text { 48. Keeps people at distance } \\
\text { 54. Gregarious } \\
\text { 4. Talkative } \\
\text { 28. Tends to arouse liking in people } \\
\text { 35. Has warmth; compassionate }\end{array}$ \\
\hline E2: Gregariousness ${ }^{a, b}$ & $\begin{array}{r}.60 \\
-.42 \\
.40 \\
-.36 \\
.34\end{array}$ & $\begin{array}{l}\text { 54. Gregarious } \\
\text { 48. Keeps people at distance } \\
\text { 92. Has social poise } \\
\text { 1. Critical, skeptical } \\
\text { 35. Has warmth, compassionate }\end{array}$ \\
\hline E3: Assertiveness ${ }^{\mathbf{a}, \mathbf{b}}$ & $\begin{array}{r}.49 \\
.37 \\
-.37 \\
.35 \\
-.33\end{array}$ & $\begin{array}{l}\text { 52. Behaves in assertive fashion } \\
\text { 4. Talkative } \\
\text { 30. Gives up in face of frustration } \\
\text { 98. Verbally fluent } \\
\text { 42. Reluctant to commit to action }\end{array}$ \\
\hline
\end{tabular}

(Continued) 
TABLE 2 (Continued)

\begin{tabular}{|c|c|c|}
\hline NEO-PI-R Facet Scale & $\mathbf{r}$ & CQS Item \\
\hline \multirow[t]{5}{*}{ E4: Activity ${ }^{\mathrm{a}, \mathrm{b}}$} & .49 & 20. Has rapid personal tempo \\
\hline & .36 & 26. Is productive \\
\hline & .32 & 71. Has high aspiration level \\
\hline & -.32 & 97. Emotionally bland \\
\hline & .28 & 52. Behaves in assertive fashion \\
\hline \multirow[t]{5}{*}{ E5: Excitement Seeking ${ }^{a, b}$} & .28 & 80. Interested in opposite sex \\
\hline & .24 & 52. Behaves in assertive fashion \\
\hline & .24 & 73. Eroticizes situations \\
\hline & -.21 & 30. Gives up in face of frustration \\
\hline & -.21 & 69. Bothered by demands \\
\hline \multirow[t]{5}{*}{ E6: Positive Emotions ${ }^{\mathbf{a}}$} & .37 & 4. Talkative \\
\hline & .35 & 84. Is cheerful \\
\hline & -.34 & 97. Emotionally bland \\
\hline & -.33 & 48. Keeps people at distance \\
\hline & .33 & 64. Perceptive of interpersonal cues \\
\hline \multirow[t]{5}{*}{ O1: Fantasy ${ }^{a, b}$} & .57 & 46. Engages in fantasy and daydreams \\
\hline & -.31 & 7. Favors conservative values \\
\hline & -.28 & 2. Genuinely dependable, responsible \\
\hline & .26 & 15. Skilled in play and humor \\
\hline & -.26 & 25. Tends toward overcontrol of impulses \\
\hline \multirow[t]{5}{*}{ O2: Aesthetics ${ }^{\mathrm{a}, \mathrm{b}}$} & .60 & 66. Is aesthetically reactive \\
\hline & .31 & 64. Perceptive of interpersonal cues \\
\hline & .30 & 90. Concerned with philosophical problems \\
\hline & -.27 & 7. Favors conservative values \\
\hline & .25 & 15. Skilled in play and humor \\
\hline \multirow[t]{5}{*}{ O3: Feelings ${ }^{\mathbf{a}}$} & -.43 & 97. Emotionally bland, has flattened affect \\
\hline & -.34 & 7. Favors conservative values \\
\hline & .29 & 64. Perceptive of interpersonal cues \\
\hline & -.27 & 14. Genuinely submissive \\
\hline & -.26 & 48. Keeps people at distance \\
\hline \multirow[t]{5}{*}{ O4: Actions $^{\mathrm{a}}$} & .30 & 64. Perceptive of interpersonal cues \\
\hline & -.28 & 25. Tends toward overcontrol of impulses \\
\hline & -.27 & 7. Favors conservative values \\
\hline & -.26 & 12. Tends to be self-defensive \\
\hline & .25 & 92. Has social poise \\
\hline \multirow[t]{5}{*}{ O5: Ideas $^{\mathrm{a}}$} & .45 & 8. Has high degree of intellectual capacity \\
\hline & .44 & 51. Values intellectual matters \\
\hline & .35 & 90. Concerned with philosophical problems \\
\hline & .32 & 3. Has wide range of interests \\
\hline & -.28 & 7. Favors conservative values \\
\hline \multirow{5}{*}{ O6: Values ${ }^{\mathrm{a}, \mathrm{b}}$} & -.45 & 7. Favors conservative values \\
\hline & -.32 & 41. Is moralistic \\
\hline & .26 & 62. Rebellious, nonconforming \\
\hline & -.23 & 14. Basically submissive \\
\hline & .23 & 8. Has high degree of intellectual capacity \\
\hline
\end{tabular}

(Continued) 
TABLE 2 (Continued)

\begin{tabular}{|c|c|c|}
\hline NEO-PI-R Facet Scale & $\mathbf{r}$ & CQS Item \\
\hline A1: Trust ${ }^{\mathbf{a}, \mathbf{b}}$ & $\begin{array}{r}-.54 \\
-.38 \\
-.33 \\
.33 \\
.30\end{array}$ & $\begin{array}{l}\text { 49. Basically distrustful } \\
\text { 38. Has hostility toward others } \\
\text { 1. Critical, skeptical } \\
\text { 84. Is cheerful } \\
\text { 92. Has social poise }\end{array}$ \\
\hline A2: Straightforwardness ${ }^{a, b}$ & $\begin{array}{r}-.42 \\
.33 \\
-.26 \\
-.25 \\
-.24\end{array}$ & $\begin{array}{l}\text { 37. Is guileful, deceitful, manipulative } \\
\text { 17. Behaves in sympathetic manner } \\
\text { 91. Is power oriented } \\
\text { 52. Behaves in assertive fashion } \\
\text { 46. Engages in fantasy and daydreams }\end{array}$ \\
\hline A3: Altruism ${ }^{\mathbf{a}, \mathbf{b}}$ & $\begin{array}{r}-.34 \\
.33 \\
-.33 \\
.33 \\
.30\end{array}$ & $\begin{array}{l}\text { 49. Basically distrustful } \\
\text { 35. Has warmth, compassionate } \\
\text { 1. Critical, skeptical } \\
\text { 28. Tends to arouse liking in people } \\
\text { 5. Behaves in giving way }\end{array}$ \\
\hline A4: Compliance ${ }^{a, b}$ & $\begin{array}{r}.36 \\
-.36 \\
-.35 \\
-.28 \\
-.28\end{array}$ & $\begin{array}{l}\text { 17. Behaves in sympathetic manner } \\
\text { 94. Expresses hostile feelings directly } \\
\text { 52. Behaves in assertive fashion } \\
\text { 38. Has hostility toward others } \\
\text { 62. Rebellious, nonconforming }\end{array}$ \\
\hline A5: Modesty ${ }^{a, b}$ & $\begin{array}{r}-.31 \\
-.25 \\
.23 \\
-.20 \\
-.20\end{array}$ & $\begin{array}{l}\text { 8. Has high degree of intellectual capacity } \\
\text { 52. Behaves in assertive fashion } \\
\text { 17. Behaves in sympathetic manner } \\
\text { 46. Engages in fantasy and daydreams } \\
\text { 27. Shows condescending behavior }\end{array}$ \\
\hline A6: Tender-Mindedness ${ }^{a, b}$ & $\begin{array}{r}-.32 \\
.30 \\
-.29 \\
.27 \\
.24\end{array}$ & $\begin{array}{l}\text { 49. Basically distrustful } \\
\text { 17. Behaves in sympathetic manner } \\
\text { 1. Critical, skeptical } \\
\text { 35. Has warmth, compassionate } \\
\text { 10. Anxiety expressed in bodily symptoms }\end{array}$ \\
\hline C1: Competence & $\begin{array}{r}.31 \\
.31 \\
.26 \\
-.24 \\
-.23\end{array}$ & $\begin{array}{l}\text { 26. Is productive } \\
\text { 75. Clearcut, consistent personality } \\
\text { 8. High degree of intellectual capacity } \\
\text { 82. Fluctuating moods } \\
\text { 13. Thin-skinned, sensitive to slights }\end{array}$ \\
\hline C2: Order ${ }^{a, b}$ & $\begin{array}{r}.42 \\
.27 \\
-.19 \\
.18 \\
-.17\end{array}$ & $\begin{array}{l}\text { 6. Is fastidious } \\
\text { 26. Is productive } \\
\text { 39. Has unconventional thought processes } \\
\text { 20. Has rapid personal tempo } \\
\text { 42. Reluctant to commit to action }\end{array}$ \\
\hline C3: Dutifulness ${ }^{a, b}$ & $\begin{array}{r}.39 \\
.32 \\
-.26 \\
.25 \\
.24\end{array}$ & $\begin{array}{l}\text { 2. Genuinely dependable, responsible } \\
\text { 75. Clearcut, consistent personality } \\
\text { 37. Is guileful, deceitful, manipulative } \\
\text { 70. Behaves in ethically consistent manner } \\
\text { 26. Is productive }\end{array}$ \\
\hline
\end{tabular}


TABLE 2 (Continued)

\begin{tabular}{|c|c|c|}
\hline NEO-PI-R Facet Scale & $\mathbf{r}$ & CQS Item \\
\hline \multirow[t]{5}{*}{ C4: Achievement Striving ${ }^{\mathbf{a}, \mathbf{b}}$} & .48 & 26. Is productive \\
\hline & .41 & 71. Has high aspiration level \\
\hline & .36 & 20. Has rapid personal tempo \\
\hline & -.33 & 42. Reluctant to commit to action \\
\hline & -.30 & 30. Gives up in face of frustration \\
\hline \multirow[t]{5}{*}{ C5: Self-Discipline ${ }^{b}$} & .49 & 26. Is productive \\
\hline & .28 & 75. Clearcut, consistent personality \\
\hline & -.26 & 55. Is self-defeating \\
\hline & .26 & 20. Has rapid personal tempo \\
\hline & -.26 & 42. Reluctant to commit to action \\
\hline \multirow[t]{5}{*}{ C6: Deliberation ${ }^{\mathrm{a}, \mathrm{b}}$} & .29 & 75. Clearcut, consistent personality \\
\hline & .23 & 24. Prides self on being rational \\
\hline & .22 & 60. Has insight into own motives \\
\hline & .20 & 70. Behaves in ethically consistent manner \\
\hline & -.18 & 62. Rebellious, nonconforming \\
\hline
\end{tabular}

Note. NEO-PI-R = Revised NEO Personality Inventory, CQS = California Q-Set, $\mathrm{N}=$ Neuroticism, $\mathrm{E}=$ Extraversion, $\mathbf{O}=$ Openness to Experience, $\mathbf{A}=$ Agreeableness, $\mathbf{C}=$ Conscientiousness. $N=380$. The five largest correlates are given for each facet scale. All correlations are significant at $p<.01$.

${ }^{\text {a }}$ Facet correctly identified from correlates by first judge. ${ }^{b}$ Facet correctly identified firom correlates by second judge.

Modesty is negatively associated with intellectual capacity, but it makes perfect sense when it is recalled that this is a self-Q-sort: Modest individulals disclaim superior intellect.

But it would be a mistake to assume that this set of correlates exhausts the meaning of the facet scales. Many important correlates are not represented in the pool of CQS items. Individuals who wish to understand NEO-PI-R facet scales in more detail are invited to study the definitions, items, and adjective and scale correlates given in the Manual (Costa \& McCrae, 1992c).

\section{FACTOR ANALYSIS AND FACET ANALYSIS}

In its original sense, factor analysis is a technique for analyzing variables in terms of the underlying factors that account for their covariation with other variables. In practice, this analysis is usually somewhat circular, because the factors themselves are inferred from the same variables that they are supposed to explain. However, if there are enough recognizable markers in an analysis, the procedure can be informative. For example, Table 1 shows that Gregariousness is a relatively pure measure of $\mathrm{E}$, whereas Assertiveness is influenced not only by $\mathrm{E}$, but also by standing on $\mathrm{N}, \mathrm{A}$, and $\mathrm{C}$. Attention to 
secondary (and additional) loadings provides a fuller understanding of what each variable means.

But it is also possible to reverse this process and interpret factors in terms of the facet loadings. We might say, for example, that the Openness to Aesthetics and to Ideas are more central to the $O$ factor in Table 1 than are Openness to Actions and to Values. It has been customary for years to interpret a factor chiefly in light of its strongest loading variables.

There is, however, an extension of this idea that avoids the circularity of normal factor analysis: the analysis of externally derived factors or scales in terms of specific facets-a procedure that might be called facet analysis. A number of alternative measures of the five factors have been offered, and despite differences in labels (Digman, 1990), there is empirical evidence of convergence among them at a global level (e.g., Briggs, 1992). The different interpretations of the factors may, however, point to different emphases that would become apparent through facet analysis. More generally, any scale can be understood by its correlates, and the 30 facets of the NEO-PI-R provide a broad representation of traits that can yield a detailed portrait of the construct being measured.

\section{Adjective Measures of the FFM}

We recently conducted a study in which peer raters of BLSA participants completed the NEO-PI-R and either Wiggins's (Trapnell \& Wiggins, 1990) or Goldberg's (1990) measure of the FFM (Costa \& McCrae, 1992a). At the factor level, there was substantial agreement: Correlations with NEO-PI-R factors ranged from .70 to .78 for Wiggins's Revised Interpersonal Adjective Scales-Big Five Version (IASR-B5), and from .45 to .77 for Goldberg's Transparent Trait Rating Form (TTRF). But a more detailed evaluation of convergence can be made by examining the correlations of the two instruments with the facets of the NEO-PI-R, shown in Table 3.

Four results in Table 3 are noteworthy:

1. The TTRF Emotional Stability scale, which includes angry, irritable, temperamental and envious among its 10 items, is more strongly related to low A facets than high $\mathrm{N}$ facets. Peer raters, in particular, may confuse the experience of anger $(\mathrm{N})$ with its outward expression (low $A$ ).

2. The Dominance and Love scales of the IASR-B5 do not correspond directly to NEO-PI-R E and A, but to a disagreeable form of $E$ and an extraverted form of $A$, respectively; this is a rotational difference that has been noted before in self-report data (McCrae \& Costa, 1989).

3. Both the TTRF and the IASR-B5 have relatively narrow measures of Openness, corresponding chiefly to NEO-PI-R Openness to Ideas. This may be due to the lack of English-language adjectives expressing other aspects of Openness (McCrae, 1990), or it may suggest that peer raters are chiefly attentive to intellectual aspects of $O$. 
TABLE 3

Correlations of Wiggins' and Goldberg's Measures With NEO-PI-R Facets in Peer Ratings

\begin{tabular}{|c|c|c|c|c|c|c|c|c|c|c|}
\hline \multirow[b]{3}{*}{ NEO-PI-R Facet Scale } & \multicolumn{10}{|c|}{ Factor } \\
\hline & \multicolumn{2}{|c|}{$N$} & \multicolumn{2}{|c|}{$E$} & \multicolumn{2}{|c|}{$O$} & \multicolumn{2}{|c|}{$\boldsymbol{A}$} & \multicolumn{2}{|c|}{$C$} \\
\hline & $\boldsymbol{W}$ & $G$ & $W$ & $G$ & $W$ & $G$ & $\boldsymbol{W}$ & $G$ & $W$ & $G$ \\
\hline N1: Anxiety & .72 & .47 & & & & & & & & \\
\hline N2: Angry Hostility & .68 & .66 & & & & & -.54 & -.61 & & \\
\hline N3: Depression & .61 & .43 & & & & & & & & \\
\hline $\begin{array}{l}\text { N4: Self-Consciousness } \\
\text { N5: Impulsiveness }\end{array}$ & .48 & & -.43 & & & & & & & \\
\hline N6: Vulnerability & .62 & .44 & & -.40 & & & & & & -.41 \\
\hline El: Warmth & & & & .42 & & & .57 & .52 & & \\
\hline E2: Gregariousness & & & .54 & .46 & & & & & & \\
\hline E3: Assertiveness & & & .84 & .52 & & & & & & \\
\hline E4: Activity & & & .54 & .42 & & & & & & \\
\hline E5: Excitement Seeking & & & & & & & & & & \\
\hline E6: Positive Emotions & & & & .45 & & & .52 & & & \\
\hline O1: Fantasy & & & & & & & & & & \\
\hline O2: Aesthetics & & & & & & .49 & & & & \\
\hline O3: Feelings & & & & & & & & & & \\
\hline O4: Actions & & & & .40 & & & & & & \\
\hline $\begin{array}{l}\text { O5: Ideas } \\
\text { O6: Values }\end{array}$ & & & & & .78 & .50 & & & & \\
\hline A1: Trust & -.45 & -.59 & & & & & .66 & .66 & & \\
\hline A2: Straightforwardness & & -.61 & -.52 & & & & .57 & .60 & & \\
\hline A3: Altruism & & -.44 & & & & & .75 & .68 & & \\
\hline A4: Compliance & & -.57 & -.64 & & & & .48 & .64 & & \\
\hline A5: Modesty & & -.50 & -.47 & & & & .51 & .64 & & \\
\hline A6: Tender-Mindedness & & & & & & & .57 & .57 & & \\
\hline $\mathrm{C1}$ : Competence & & & & & & .43 & & & .61 & .57 \\
\hline C2: Order & & & & & & & & & .74 & .51 \\
\hline C3: Dutifulness & & & & & & & & & .56 & .59 \\
\hline C4: Achievement Striving & & & .47 & & & & & & .46 & .54 \\
\hline C5: Self-Discipline & & & & & & & & & .72 & .64 \\
\hline C6: Deliberation & & & & & & & & & .45 & .45 \\
\hline
\end{tabular}

Note. NEO-PI-R = Revised NEO Personality Inventory, $\mathrm{N}=$ Neuroticism, $\mathrm{E}=$ Extraversion, $\mathrm{O}=$ Openness to Experience, $\mathrm{A}=$ Agreeableness, $\mathrm{C}=$ Conscientiousness, $\mathbf{W}=$ Wiggins's Revised Interpersonal Adjective Scales-Big Five Version (IASR-B5), $\mathbb{G}=$ Goldberg's Transparent Trait Rating Form (TTRF). $N=150$ for IASR-B5, $N=123$ for TTRF. Correlations above \pm .40 are given; all are significant at $p<.001$. 
4. The Agreeableness and Conscientiousness scales of the IASR-B5 and the TTRF appear to cover the same range of traits found in the NEO-PI-R.

The NEO-PI-R is not the gold standard by which other conceptualizations of the FFM should be judged, but its facets do provide $a$ standard by which different conceptualizations can be compared. If researchers desire to use Neuroticism scales that are relatively independent of antagonism, then the Wiggins scale may be a better choice than the Goldberg scale. If they believe that Extraversion should include warmth and positive emotions as well as assertiveness, Table 3 suggests they should choose the Goldberg scale over Wiggins's. ${ }^{3}$

\section{The Hogan Personality Inventory}

The Hogan Personality Inventory (HPI; R. Hogan, 1986) offers yet another version of the FFM. In the HPI, $\mathrm{N}$ is represented as low Adjustment, $\mathrm{O}$ as Intellectance, $\mathrm{A}$ as Likeability, and $\mathrm{C}$ as Prudence; $\mathrm{E}$ is broken into Sociability and Ambition. Correlations between the HPI and the NEO-PI-R domains are generally smaller than those seen with adjective scales, and they are somewhat confusing in pattern. There is a clear correspondence between HPI Adjustment and $\mathrm{N}, r=-.81$, and HPI Sociability and $\mathrm{E}, r=.60$, but HPI Prudence is almost as closely related to $\mathrm{A}$ as to $\mathrm{C} . r=.42$ versus $r=.44$, and the correlation between HPI Intellectance and $\mathrm{O}$ is barely significant at $r=$ .21 .

Analyses of the HPI that merely examine its scales at the domain level typically show modest to moderate convergence with alternative measures of the FFM (e.g., Briggs, 1992). Facet analysis provides a much more detailed account of the nature of the correspondences and differences that can be helpful in interpreting HPI scales. Table 4 presents a facet analysis using data from 124 BLSA participants who completed both instruments (on different occasions). In addition, self-reports on the HPI were also correlated with spouse ratings on the NEO-PI-R for a small subsample; these data allow an assessment of the cross-observer replicability of the findings. The Adjustment and Sociability scales are not problematic, but the other HPI scales require comment.

Although it is considered by R. Hogan to be a subdivision of E, Ambition is actually related to facets from three domains, notably Assertiveness and Activity from E, low Compliance and Modesty from A, and high Achievement Striving from C. Ambitious people are dominant, aggressive, and

\footnotetext{
${ }^{3}$ Alternatively, they could use the Gregarious-Extraverted octant scale of the Interpersonal Adjective Scales-Big Five Version, which is strongly correlated, $r s=.63$ and .61 , with both Warmth and Positive Emotions in peer ratings on the Revised NEO Personality Inventory.
} 
achievement oriented (cf. J. A. Johnson \& Ostendorf, 1993). These are understandable correlates, especially when it is recalled that in early versions of the HPI, Ambition was measured by such Homogeneous Item Clusters (HICs) as Leadership, Competitive, and Mastery Motive. But in the NEO-PI-R the constituent elements of Ambition do not covary to form a single factor; their combination in the HPI seems to present a challenge to the structure of the FFM itself.

In fact, however, R. Hogan's own (1986) factor analysis of the HPI showed that these HICs did not define a single factor. Leadership primarily loaded on a factor that $\mathrm{R}$. Hogan labeled Histrionics and that included the HICs Enjoys Crowds and Likes Parties; we would interpret this factor as E, and conclude that Leadership loads on the same factor as NEO-PI-R Assertiveness. The Competitive HIC loaded chiefly on a factor labeled Creativity, whereas Mastery Motive was the best definer of a factor R. Hogan labeled Work Ethic - a factor we would interpret as C. Thus, it appears that Ambition is a multidimensional construct rather than a basic factor of personality; as R. Hogan noted, "The Ambition scale is not as cohesive as the other primary scales" (1986, p. 10).

In Table 4, Intellectance shows a substantial correlation with Openness to Ideas, and a modest correlation with Openness to Aesthetics, but it is otherwise unrelated to facets of $0 .{ }^{4}$ Yet both $\mathrm{O}$ and Intellectance have been regarded as measures of the fifth factor discovered in lexical analyses, and Goldberg (1992) reported correlations of .46 and .39 , respectively, between these two scales and his fifth factor, which he labeled Intellect. It would appear that both scales share some common elements with a factor defined by such adjectives as intelligent, imaginative, and complex, but that they differ in the selection of other elements in the domain.

Table 4 shows that HPI Likeability combines elements of $E$ and $A$ in much the same way that Wiggin's Love factor does-this is a common rotational variant that occurs because traits that form the interpersonal circumplex do not exhibit clear simple structure. When only interpersonal traits are considered, there is no compelling reason to prefer one rotation over the other. We have adopted the view that $\mathrm{E}$ has an affective as well as an interpersonal aspect (cf. Watson \& Clark, in press), and we prefer a rotation in which Positive Emotions loads cleanly on the E factor, as Table 1 shows (McCrae \& Costa, 1989). Table 4 shows that in the HPI system, Positive Emotions is divided between Sociability and Likeability.

Finally, HPI Prudence, like Ambition, appears to combine a number of disparate elements, especially Straightforwardness from A, and Order and Dutifulness from C. Prudence is also related to low Angry Hostility, low

\footnotetext{
${ }^{4}$ Data from P. D. Trapnell (personal communication, April 9, 1992) on the Hogan Personality Inventory and NEO Personality Inventory in a college sample $(N=581)$ show somewhat stronger correlations, ranging from .13 between Intellectance and Openness to Values to .57 between Intellectance and Openness to Ideas. The correlation with total Openness was .41.
} 
TABLE 4

Correlations of Hogan Personality Inventory Primary Scales With NEO-PI-R Facet Scales

\begin{tabular}{|c|c|c|c|c|c|c|}
\hline \multirow[b]{2}{*}{ NEO-PI-R Facet Scale } & \multicolumn{6}{|c|}{ Hogan Personality Inventory Scale } \\
\hline & $A D J$ & $S O C$ & $A M B$ & INT & $L I K$ & $P R U$ \\
\hline N1: Anxiety & $-.65^{\mathrm{a} * * *}$ & .02 & -.09 & $-.20^{*}$ & -.16 & -.14 \\
\hline N2: Angry Hostility & $-.44^{* * *}$ & $.29 * *$ & .15 & -.15 & $-.35^{a * * *}$ & $-.28 * *$ \\
\hline N3: Depression & $-.73^{a * * *}$ & .02 & -.08 & $-.23^{*}$ & $-.26^{\mathrm{a} * *}$ & -.10 \\
\hline N4: Self-Consciousness & $-.73 * * *$ & -.11 & -.17 & $-.22 *$ & $-.24 * *$ & .05 \\
\hline N5: Impulsiveness & $-.38^{\mathrm{a} * * *}$ & $.24^{\mathrm{a} * *}$ & .03 & $-.25^{* *}$ & -.07 & $-.26^{* *}$ \\
\hline N6: Vulnerability & $-.70^{* * *}$ & -.02 & $-.25^{* *}$ & -.15 & -.14 & -.06 \\
\hline E1: Warmth & $.30^{* * *}$ & $.23^{* *}$ & .15 & -.01 & $.54^{\mathrm{a} * * *}$ & .10 \\
\hline E2: Gregariousness & .13 & $.45^{\mathrm{a} * * *}$ & .16 & $-.19^{a *}$ & $.50^{\mathrm{a} * * *}$ & -.16 \\
\hline E3: Assertiveness & $.41^{* * *}$ & $.40^{* * *}$ & $.62^{\mathrm{a} * * *}$ & .03 & $.26 * *$ & -.14 \\
\hline E4: Activity & $.27^{* *}$ & $.44^{a * * *}$ & $.50^{* * *}$ & -.02 & .05 & $-20^{a *}$ \\
\hline E5: Excitement Seeking & -.09 & $.40^{2 * * *}$ & $.24^{* *}$ & -.07 & .06 & $-.35^{\mathrm{a} * * *}$ \\
\hline E6: Positive Emotions & .14 & $.41^{a * * *}$ & $.27^{* *}$ & -.05 & $.34^{\mathrm{a} * * *}$ & $-.21 *$ \\
\hline O1: Fal & $-.34^{* *}$ & $.29^{* * *}$ & .01 & .00 & .07 & $-.24^{* *}$ \\
\hline O2: Aesthetics &.$\infty 0$ & $.19^{*}$ & .07 & $.23^{a_{*}^{*}}$ & .14 & -.15 \\
\hline O3: Feelings & -.10 & $.29 * *$ & $.20^{*}$ & -.04 & .13 & $-.25 * *$ \\
\hline O4: Actions & .07 & $.25^{* *}$ & .02 & .08 & .14 & $-.36 * * *$ \\
\hline O5: Ideas & .13 & .12 & .15 & $.47^{\mathrm{a} * * *}$ & -.03 & -.13 \\
\hline O6: Values & .10 & .13 & .15 & -.03 & .04 & $-.25^{* *}$ \\
\hline A1: Trust & $.38 * * *$ & .02 & .03 & .16 & $.35^{* * *}$ & .00 \\
\hline A2: Straightforwardness & .09 & $-.40^{* * *}$ & $-.40^{* * *}$ & .03 & .08 & $.50^{* * *}$ \\
\hline A3: Altruism & .17 & -.04 & -.01 & -.01 & $.37^{\mathrm{a} * * *}$ & $.20^{*}$ \\
\hline A4: Compliance & .07 & $-.38 * * *$ & $-.45^{\mathrm{a} * * *}$ & -.03 & $.26^{\mathrm{a} * *}$ & $.36 * * *$ \\
\hline A5: Modesty & $-.22 *$ & $-.50 * * *$ & $-.47^{\mathrm{a} * * *}$ & -.05 & .01 & $.33 * * *$ \\
\hline A6: Tender-Mindedness & .10 & .02 & -.06 & -.03 & $.28 * *$ & .10 \\
\hline C1: Competence & $.52^{* * *}$ & .05 & $.29^{* *}$ & $.20^{*}$ & .17 & $.23^{*}$ \\
\hline C2: Order & $.19^{*}$ & -.12 & .00 & .01 & .15 & $.46^{* * *}$ \\
\hline C3: Dutifulness & $.35^{* * *}$ & -.09 & .15 & .11 & .06 & $.42 * * *$ \\
\hline C4: Achievement Striving & $.33^{* * *}$ & .10 & $.45^{* * *}$ & .19 & -.02 & $.18^{*}$ \\
\hline C5: Self-Discipline & $.46^{* * *}$ & -.04 & $.23^{*}$ & .03 & .12 & $.35 * * *$ \\
\hline C6: Deliberation & $.31 * * *$ & -.14 & .02 & .12 & .04 & $.39 * * *$ \\
\hline
\end{tabular}

Note. NEO-PI-R = Revised NEO Personality Inventory, ADJ = Adjustment, SOC $=$ Sociability, AMB = Ambition, INT = Intellectance, LIK = Likability, PRU = Prudence, $\mathbf{N}$ $=$ Neuroticism, $\mathrm{E}=$ Extraversion, $\mathrm{O}=$ Openness to Experience, $\mathrm{A}=$ Agreeableness, $\mathrm{C}=$ Conscientiousness. $N=124$.

aSignificant as a replication using spouse ratings of NEO-PI-R scales, $N=29, p<.05$, one-tailed.

${ }^{*} p<.05 .{ }^{* *} p<.01 .{ }^{* * *} p<.001$. 
Excitement Seeking, and low Openness to Actions. Clearly, there is no one-to-one correspondence between Prudence and C.

In 1992 R. Hogan and J. Hogan published a revised version of the HPI, retaining the original HICs but reassigning some to different scales. The changes were not trivial: Correlations between the original and revised personality scales ranged from .62 for Ambition to .90 for Sociability. For two scales, the changes take the HPI further from the conception of the FFM embodied in the NEO-PI-R. The new Ambition scale, which includes the HICs No Depression and No Social Anxiety, is most strongly related to N, $r$ $=-.62$, rather than $\mathrm{E}, r=.55$; and the revised Likeability scale is only marginally related to $\mathrm{A}$, its hypothesized counterpart, $r=.22$.

Two other changes bring the instruments somewhat closer together. First, the correlation between Prudence and $\mathrm{C}$ increased from .44 to .55; at the facet level, the revised Prudence scale showed correlations ranging from .29 for Achievement Striving to .53 for Dutifulness. Second, Intellectance was subdivided into two scales, revised Intellectance and School Success. The latter scale, which is correlated with years of education in the BLSA sample, $r=.39$, is unrelated to NEO-PI-R O, $r=.05$. By contrast, the revised Intellectance scale, which is not significantly related to years of education, shows a substantial correlation with $\mathrm{O}, r=.50$. It is significantly related to Openness to Fantasy (.27), Aesthetics (.42), Actions (.29), and Ideas (.53). The distinction between Intellectance and School Success mirrors the distinction we have made between $O$ and intelligence (McCrae \& Costa, 1985, in press).

\section{Empirically-Based Occupational Scales}

Facet analysis may be particularly useful in understanding criterion-keyed scales. For example, R. Hogan (1986) contrasted the responses of felons with those of students and blue-collar workers to create the HPI Reliability scale. Gough (1984) used two criteria for selecting items for a Managerial Potential scale: performance ratings of military officers, and preferential item endorsement by bank managers. California Psychological Inventory (CPI; Gough, 1987) items meeting both these criteria were combined into a 34item scale. Such scales are often complex and multidimensional, measuring a syndrome of relevant characteristics rather than a unified psychological construct. If we wish to understand what such a scale is measuring, we can use Gough's (1965) conceptual analysis approach, one step of which requires that we correlate the scale with a wide array of personality traits from which we can infer the meaning of the scale. The facets of the NEO-PI-R may be particularly useful in this step of conceptual analysis, because they systematically sample all five major factors of personality.

Table 5 reports correlations of NEO-PI-R facet scales with empiricallybased occupational scales from two instruments, the revised HPI and the 
TABLE 5

Correlations of Revised HPI and CPI Occupational Scales With NEO-PI-R Facet Scales

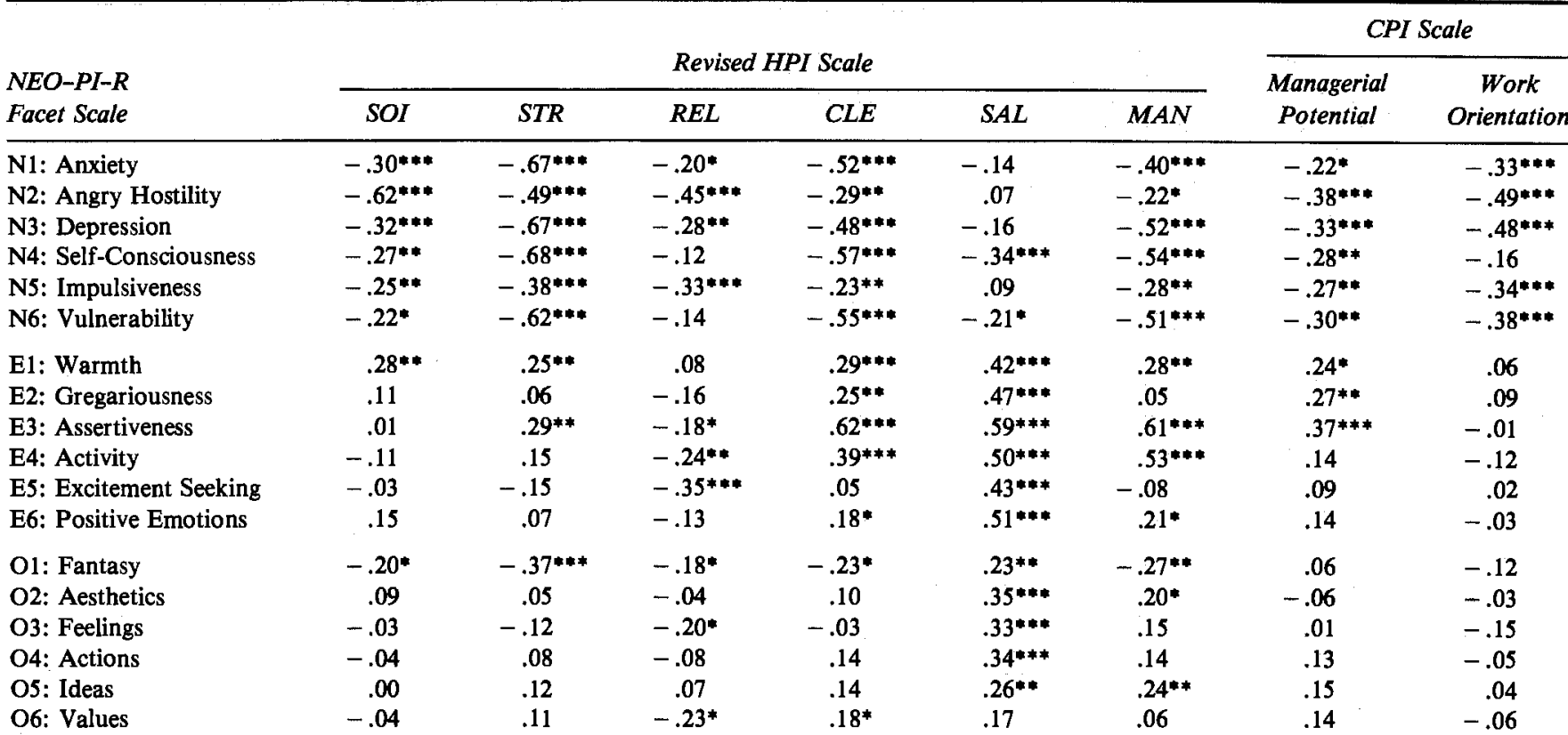




\begin{tabular}{|c|c|c|c|c|c|c|c|c|}
\hline A1: Trust & $.21^{*}$ & $.29 * *$ & .13 & $.22^{*}$ & .16 & .18 & $.34^{* * *}$ & $.21^{*}$ \\
\hline A2: Straightforwardness & $.35^{* * *}$ & .09 & $.52^{* * *}$ & $-.19 *$ & $-.36^{* * *}$ & -.04 & -.06 & .17 \\
\hline A4: Compliance & $.52 * * *$ & .11 & $.53^{* * *}$ & -.13 & $-.32 * * *$ & -.14 & $.30^{* *}$ & $.34^{* * * *}$ \\
\hline A6: Tender-Mindedness & $.27^{* *}$ & .09 & .10 & .14 & .14 & .08 & .08 & .08 \\
\hline C1: Competence & $.22^{*}$ & $.48^{* * *}$ & $.26^{* *}$ & $.44^{* * *}$ & $.18^{*}$ & $.63^{* * *}$ & .14 & $.23^{*}$ \\
\hline C2: Order & $.18^{*}$ & $.24^{* *}$ & $.30^{* * *}$ & .11 & -.14 & $.25^{* *}$ & $.21^{*}$ & .08 \\
\hline C5: Self-Discipline & $.19^{*}$ & $.41 * * *$ & $.28 * 0 * 0$ & $.36 * * *$ & .02 & $.56^{* * *}$ & $.24^{*}$ & $.26^{* *}$ \\
\hline C6: Deliberation & $.30^{* * *}$ & $.36 * * *$ & $.41^{* * *}$ & $.22 *$ & -.09 & $.32^{* * *}$ & .15 & $.32^{* * *}$ \\
\hline
\end{tabular}

Note. NEO-PI-R = Revised NEO Personality Inventory, HPI = Hogan Personality Inventory, CPI = Califomia Psychological Inventory, SOI $=$ Service Orientation, STR $=$ Stress Tolerance, REL = Reliability, CLE = Clerical Potential, SAL = Sales Potential, MAN = Managerial Potential, $\mathrm{N}=$ Neuroticism, $\mathrm{E}=$ Extraversion, $\mathrm{O}=$ Openness to Experience, $\mathrm{A}=$ Agreeableness, $\mathrm{C}=\mathrm{Conscientiousness}$. $N=124$ for HPI scales, $N=99$ for CPI scales.

${ }^{*} p<.05 .{ }^{* *} p<.01 .{ }^{* * *} p<.001$. 
CPI. All scales are keyed in the occupationally desirable direction, and they show generally similar patterns. Desirable employees appear to be well adjusted and conscientious. It is not surprising that $\mathrm{C}$ emerges as an important element in job performance; meta-analyses have identified $\mathrm{C}$ as a predictor of successful performance in a wide variety of occupations (Barrick \& Mount, 1991). The contribution of $\mathrm{N}$ to job performance is less clear.

The detailed information from a facet analysis can either support or call into question the construct validity of a scale. Consider the revised HPI Sales Potential scale, developed by contrasting the responses of top sales representatives with those of executives to "identify people who are socially skilled, self-assured, assertive, and can create interest in products and services" (R. Hogan \& J. Hogan, 1992, p. 71). Correlations in Table 5 show that high scorers on this scale are low in Self-Consciousness and Modesty and high in $E$, especially Assertiveness. They are also consistently high in facets of $O$, suggesting that exceptional salespeople are original and inventive as well as being socially skilled. This scale appears to have captured the characteristics it was intended to tap.

Table 5 provides the basis for a more critical evaluation of Gough's (1985) Work Orientation scale. This was intended to operationalize Weber's (1904/1930) concept of the Protestant Ethic, and one would expect it to correlate most highly with facets of $C$ such as Dutifulness and Achievement Striving. Although there are some significant correlations with $\mathrm{C}$ facets, the largest correlations are clearly with facets of $\mathrm{N}$. This is not a chance finding; Gough himself (1985) reported correlations of Work Orientation with Maudsley Personality Inventory Neuroticism, $r=-.67$, and GuilfordZimmerman Temperament Survey Emotional Stability, $r=.78$, that confirm the strong association with $\mathrm{N}$. What those instruments did not reveal-and could not reveal because they lacked suitable facets-was the weakness of the correlation with measures of $\mathrm{C}$. In order to evaluate scales empirically it is not sufficient to correlate them with a large number of scales; the scales must systematically tap the full range of personality traits.

\section{HIERARCHICAL INTERPRETATION OF PERSONALITY PROFILES}

Although hierarchical models are common in personality trait theory, and although researchers and clinicians are familiar in general with the notion of scales and subscales, many users have limited experience in the interpretation of hierarchical personality profiles. Where does one begin? What does one do when there are discrepancies between domain and facet level interpretations? Why interpret domains at all, if all the information in the profile is contained in the facet scales? These issues require some comment.

Figure 2 presents the NEO-PI-R profile of Case A, a 32-year-old woman referred to a behavioral medicine clinic (Costa \& McCrae, 1992c, p. 20). The 


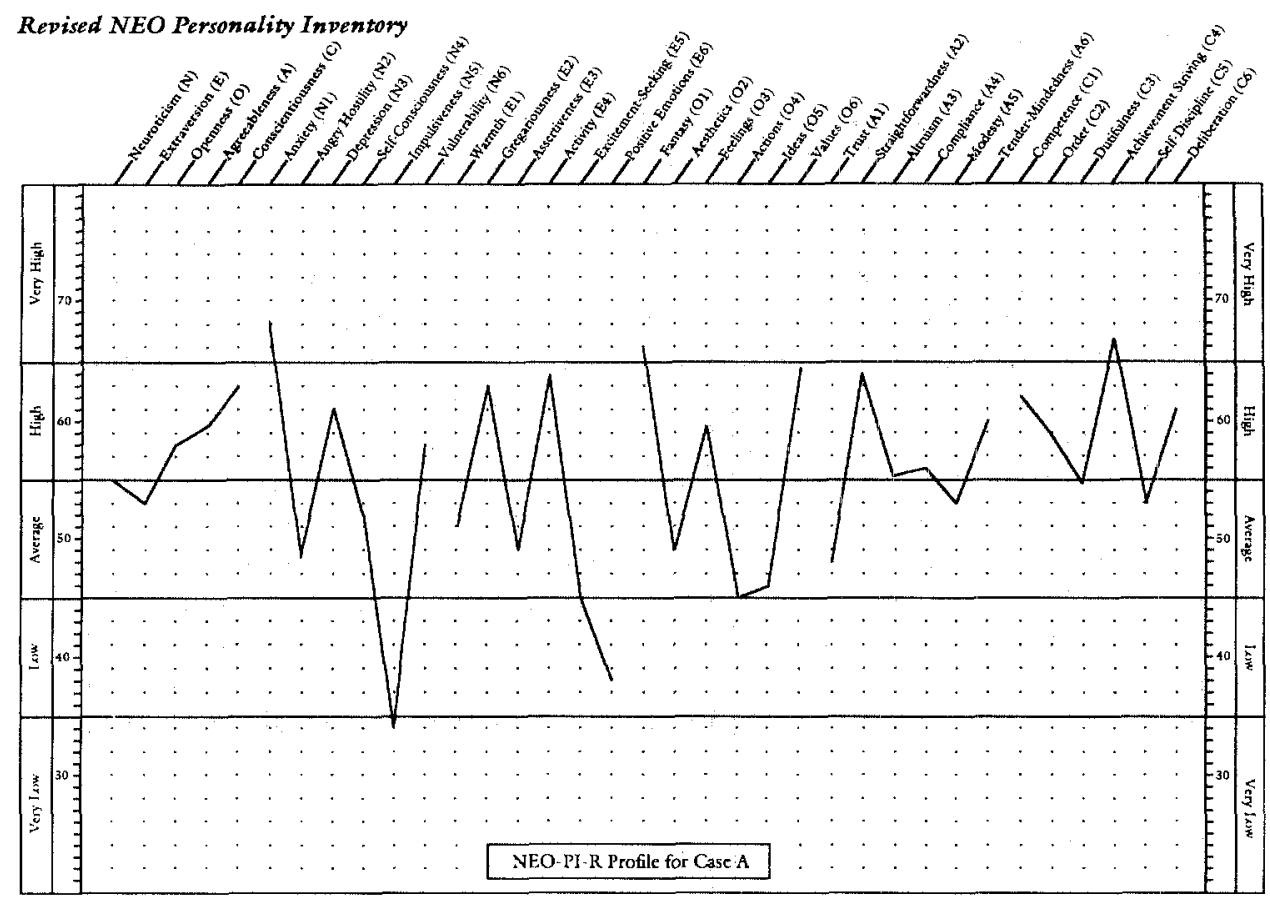

FIGURE 2 Personality profile for Case A. Adapted from Costa and McCrae (1992) and reproduced by special permission of the Publisher, Psychological Assessment Resources, Inc., 16204 North Florida Avenue, Lutz, Florida 33549, frorn the NEO Personality Inventory-Revised, by Paul Costa and Robert McCrae, Copyright (c) 1978, 1985, 1989 , 1992 by PAR, Inc. Further reproduction is prohibited without permission of PAR, Inc.

profile sheet is arranged with the five domain scores presented on the left, followed by the 30 facet scales grouped by domain-the groupings are emphasized by connecting the points of the profile within, but not across, domains. This arrangement is intended to suggest a particular strategy of interpretation: First attend to the broad domains, then to the details within each domain.

This sequence is intended to facilitate rapid understanding. In a few broad strokes, the domain scores give an idea of what the individual is like. Case A is average in $\mathrm{N}$ and $\mathrm{E}$, but high in $\mathrm{O}, \mathrm{A}$, and $\mathrm{C}$. We would probably consider her a good candidate for psychotherapy: She is not excessively emotional, willing to try new approaches to life, likely to be cooperative with the therapist, and capable of sustained effort at change (cf. Miller, 1991). We know immediately that she is very different from the typical psychotherapy patient, who scores high on $\mathrm{N}$ and low on $\mathrm{A}$ and $\mathrm{C}$.

In the computer Interpretive Report, the strategy of highlighting the most important characteristics of the individual is carried one step further. The 
body of the report begins by describing the single factor on which the individual scores most distinctively (highest or lowest), and proceeds in order of decreasing salience. For Case $\mathrm{A}$, the report would begin with a description of high $\mathrm{C}$, the most noteworthy feature of the domain profile, and then treat standing on $A, O, N$, and $E$, respectively. This approach could also easily be adopted by human interpreters, who already have experience with noting high points on personality profiles. It should be pointed out, however, that in the NEO-PI-R low points are often as important as high points: Being extremely introverted or closed is as important in determining behavior and experience as is being extremely extraverted or open.

McAdams (1992) referred to personality description at the level of the five factors as "a psychology of the stranger" (p. 348) and argued that it gives only the most superficial information that one might need to know to deal with a complete stranger. In some respects we agree with this assessment, although we do not necessarily consider it a problem. It should be recalled that the new patient is always a stranger to the clinician, and individuals-especially individuals in psychotherapy-are often strangers to themselves. Analysis of personality at the domain level is only a starting place, but it is a very good starting place.

\section{Information from Facet Scales}

A better acquaintance with the individual comes from a consideration of facets. The major difficulty here is the sheer number of them: The 30 facet scales of the NEO-PI-R will take even the experienced interpreter some time to digest. One might consider each in turn (as the Interpretive Report does), or one might choose to begin with an examination of the facets from the most salient domain. In either case, we would recommend that all the facets from a single domain be studied together, and in relation to the total domain score. Picking out a few high and low points on the facet profile is likely to give a superficial understanding of the case.

The robust factor structure of the NEO-PI-R may lead to the expectation that all the facets in a domain will show comparable levels. Case A scores high on $\mathrm{C}$, and she is within 2 points of scoring in the high range on all six $C$ facets. She appears to be higher in Achievement Striving than in Dutifulness and Self-Discipline, but the difference is fairly subtle. In this case the facet scales reinforce the impression derived from the domain scale.

But this is by no means always the case. Some scatter among facets within a domain is the rule; this scatter is not due to unreliability of measurement, because it is preserved over time (Costa, 1986) and, in general, across observers (McCrae \& Costa, 1992). Instead, it reflects real differences in standing on different but related traits. If there were no such differences there would be no point in examining facet scales separately.

Case A provides a nice illustration of this phenomenon in her $\mathrm{N}$ facet scales. Although she appears from her domain score to be average on $\mathrm{N}$, her 
$\mathrm{N}$ facet scores range from very low on Impulsiveness to very high on Anxiety. Her highest scores are on Anxiety, Depression, and Vulnerability, the purest markers of $\mathrm{N}$, so she may in fact resemble the typical psychotherapy patient more than we first suspected. (Her lower scores on Angry Hostility and Impulsiveness are understandable in terms of other factors, namely $\mathrm{A}$ and $C$, on which these two scales have secondary loadings. It would be unusual for an individual as agreeable as she is to be high on Angry Hostility, or for someone as conscientious as she is to be high on Impulsiveness.)

The $E, O$, and A domains show some scatter, and lead to more qualified statements. Instead of saying that Case A is average in her level of extraversion, we can say that she is high in Gregariousness and Activity, but low in Positive Emotions. Instead of saying she is open to experience, we can say that she is open to experience in the areas of Fantasy, Feelings, and Values. Interpretation of domains should be tentative, pending examination of individual facets.

This issue arises in computer interpretation, where the statements generated for the factor-level description are occasionally contradicted by statements about facet scales. The Interpretive Report suggests that in these cases, priority should be given to the facets: "To the extent that there is wide scatter among facet scores within a domain, interpretation of that domain and factor becomes more complex. In these cases, particular attention should be focused on the facet scales and their interpretation."

\section{The Value of Domain Interpretations}

It might be argued that the interpretation of domain scores is needless as well as occasionally misleading. After all, the domain is merely the sum of the facets: What information can it contain that the facets lack? The novice may need to limit attention to five scales, but shouldn't the expert, who has mastered conceptualization of all the facet scales, proceed to them directly?

In fact, experienced clinicians do tend to spend more time on facets and less on domains (Mutén, 1991). The information facets offer is more specific, more easily tied to the client's problems in living. Case A came to therapy because of back and neck pain probably related to her very high Anxiety score. Self-consciousness, however, was not a problem for her, and it is unlikely that she would have benefited much from an assertiveness training program. The optimal matching of treatments to persons is likely to be found at the facet level.

As Wiggins (1992, p. 529) noted, the subordinate qualities of facet scales - their concreteness, specificity, high-fidelity-_"appear to be generally regarded as more scientifically desirable than the superordinate qualities" of domains. Why, then, interpret domains at all?

One answer is that global traits have an explanatory power that specific traits lack (Funder, 1991). Explaining assertive behavior in terms of trait 
assertiveness is only modestly informative; explaining it as an expression of general extraversion "relates a specific behavioral observation to a complex and general pattern of behavior. Such movement from the specific to the general is what explanation is all about" (Funder, 1991, p. 36).

A second answer is that domain interpretation is the most basic kind of profile analysis; it combines information from several scales in meaningful ways and allows us to make more powerful inferences about personality traits and correlates that are not directly measured. Facet scales are best at predicting the specific criteria at which they are aimed, but less than optimal at predicting other, albeit related criteria. None of the NEO-PI-R facet scales measures somatic complaints, but five of the six facets of $\mathrm{N}$ are significantly related to symptom reports, and the best predictor is the full $\mathrm{N}$ domain scale (Costa \& McCrae, 1987). Similarly, all six facets of $\mathrm{O}$ are significantly related to divergent thinking abilities, but none as strongly as total O (McCrae, 1987).

Facets are designed to sample the domains from which they are drawn, not to exhaust them, and no instrument can measure all possible personality correlates. Personality inventories are useful precisely because they measure general and pervasive dispositions that influence a host of psychological and behavioral variables. By assessing a few key traits we can make educated guesses about an almost endless number of other characteristics of the individual. Scores on the five domains of the NEO-PI-R are among the most informative parts of a complete psychological assessment.

\section{SUMMARY}

For decades psychologists have known that personality traits are hierarchically organized, with many narrow, specific traits clustering to define a smaller number of broad dimensions at a higher level of abstraction. But there has been little agreement on the specification of lower level traits, and only within the past decade it has become clear that the FFM provides a reasonable representation of individual differences in personality at the highest level.

In developing the NEO-PI-R as a hierarchical measure of personality, we used a top-down strategy, beginning with the five well-established factors or domains- $N, E, O, A$, and $\mathrm{C}$ - and subdividing each into six more specific facet scales. The facets were selected to meet a series of criteria: They should represent maximally distinct aspects of the domain, be roughly equivalent in breadth, and be conceptually rooted in the existing psychological literature. Data presented here show that NEO-PI-R facet scales covary as expected to define the five factors but that they also carry specific variance that contributes to their discriminant validity.

In personality research, facet analysis provides a useful way to characterize scales and constructs. The adjective Big Five measures developed by 
Goldberg and Wiggins both show convergence with NEO-PI-R domain scales; their somewhat different conceptualizations of the factors are revealed by correlations with NEO-PI-R facet scales. Facet analysis may be particularly useful in interpreting empirically-keyed scales (such as the occupational scales of R. Hogan and Gough), which often combine aspects of several different dimensions.

In clinical practice, the interpretation of a hierarchical profile can facilitate understanding of the client. The five NEO-PI-R domain scores quickly sketch the outlines of the client's personality; facet scales fill in the details. Because they are more concretely tied to specific behaviors and experiences, it is likely that facet scales will often prove more useful than domain scales in interpreting the client's behavior and in choosing specific interventions. Domain scales remain useful for inferring many aspects of personality that are not directly measured.

\section{ACKNOWLEDGMENTS}

This article was originally prepared for publication in Advances in Psychological Assessment, J. C. Rosen, Editor, before cancellation of that series. Portions of the article were presented at the Conventions of the American Psychological Association, August, 1992, Washington, DC, and the American Psychological Society, June, 1992, San Diego.

Thanks are due to Jeffrey Herbst and Stephanie V. Stone for their assistance as judges, and to Raymond N. Wolfe, Lewis R. Goldberg, Paul D. Trapnell, and John A. Johnson for helpful comments. Joyce and Robert Hogan kindly provided scoring for the Revised Hogan Personality Inventory.

\section{REFERENCES}

Barrick, M. R., \& Mount, M. K. (1991). The Big Five personality dimensions and job performance: A meta-analysis. Personnel Psychology, 44, 1-26.

Bem, D. J., \& Funder, D. C. (1978). Predicting more of the people more of the time: Assessing the personality of situations. Psychological Review, 85, 485-501.

Block, J. (1961). The Q-sort method in personality assessment and psychiatric research. Springfield, IL: Thomas.

Briggs, S. R. (1989). The optimal level of measurement for personality constructs. In D. M. Buss \& N. Cantor (Eds.), Personality psychology: Recent trends and emerging directions (pp. 246-260). New York: Springer-Verlag.

Briggs, S. R. (1992). Assessing the five-factor model of personality description. Journal of Personality, 60, 253-293.

Buss, A. H. (1989). Personality as traits. American Psychologist, 44, 1378-1388

Costa, P. T., Jr. (1986, August). The scope of individuality. Invited address, Division 8, presented at the Annual Convention of the American Psychological Association, Los Angeles, CA.

Costa, P. T., Jr., \& McCrae, R. R. (1978). Objective personality assessment. In M. Storandt, I. C. Siegler, \& M. F. Elias (Eds.), The clinical psychology of aging (pp. 119-143). New York: 
Plenum.

Costa, P. T., Jr., \& McCrae, R. R. (1980). Still stable after all these years: Personality as a key to some issues in adulthood and old age. In P. B. Baltes \& O. G. Brim, Jr. (Eds.), Life span development and behavior (Vol. 3, pp. 65-102). New York: Academic.

Costa, P. T., Jr., \& McCrae, R. R. (1987). Neuroticism, somatic complaints, and disease: Is the bark worse than the bite? Journal of Personality, 55, 299-316.

Costa, P. T., \& McCrae, R. R. (1992a, June). Comparability of alternative measures of the five-factor model in peer ratings. Paper presented at the Annual Convention of the American Psychological Society, San Diego.

Costa, P. T., Jr., \& McCrae, R. R. (1992b). Four ways five factors are basic. Personality and Individual Differences, 13, 653-665.

Costa, P. T., Jr., \& McCrae, R. R. (1992c). Revised NEO Personality lnventory (NEO-PI-R) and NEO Five-Factor Inventory (NEO-FFI) professional manual. Odessa, FL: Psychological Assessment Resources, Inc.

Costa, P. T., Jr., \& McCrae, R. R. (1992d). Trait psychology comes of age. In T. B. Sonderegger (Ed.), Nebraska Symposium on Motivation: Psychology and Aging (pp. 169-204). Lincoln, NE: University of Nebraska Press.

Costa, P. T., Jr., \& McCrae, R. R. (1994). Stability and change in personality from adolescence through adulthood. In C. F. Halverson, G. A. Kohnstamm, \& R. P. Martin (Eds.), The developing structure of temperament and personality from infancy to adulthood (pp. 139150). Hillsdale, NJ: Lawrence Erlbaum Associates, Inc.

- Costa, P. T., Jr., McCrae, R. R., \& Dye, D. A. (1991). Facet scales for Agreeableness and Conscientiousness: A revision of the NEO Personality Inventory. Personality and Individual Differences, $12,887-898$.

Digman, J. M. (1979). The five major domains of personality variables: Analysis of personality questionnaire data in the light of the five robust factors emerging from studies of rated characteristics. Paper presented at the Annual Meeting of the Society of Multivariate Experimental Psychology, Los Angeles.

Digman, J. M. (1990). Personality structure: Emergence of the five-factor model. Annual Review of Psychology, 41, 417-440.

Eysenck, H. J., \& Wilson, G. (1976). Know your own personality. New York: Penguin.

Funder, D. C. (1991). Global traits: A Neo-Allportian approach to personality. Psychological Science, 2, 31-39.

Goldberg, L. R. (1990). An alternative "description of personality": The Big-Five factor structure. Journal of Personality and Social Psychology, 59, 1216-1229.

Goldberg, L. R. (1992). The development of markers for the Big-Five factor structure. Psychological Assessment, 4, 26-42.

Goldberg, L. R. (1993). The structure of personality traits: Vertical and horizontal aspects. In D. C. Funder, R. Parke, C. Tomlinson-Keasey, \& K. Widaman (Eds.), Studying lives through time: Personality and development (pp. 169-188). Washington, DC: American Psychological Association.

Gorsuch, R. L. (1974). Factor analysis. Philadelphia: Saunders.

Gough, H. G. (1984), A Managerial Potential scale for the California Psychological Inventory. Journal of Applied Psychology, 69, 233-240.

Gough, H. G. (1985). A Work Orientation scale for the California Psychological Inventory. Journal of Applied Psychology, 70, 505-513.

Gough, H. G. (1987). California Psychological Inventory administrator's guide. Palo Alto, CA: Consulting Psychologists Press.

Guilford, J, P. (1967). The nature of human intelligence. New York: McGraw-Hill.

$\checkmark$ Guttman, L. (1954). An outline of some new methodology for social research. Public Opinion Quarterly, 18, 395-404.

Hathaway S. R., \& McKinley, J. C. (1983). The Minnesota Multiphasic Personality Inventory 
manual. New York: Psychological Corporation.

Hofstee, W. K. B., De Raad, B., \& Goldberg, L. R. (1992). Integration of the Big Five and circumplex approaches to trait structure. Journal of Personality and Social Psychology, 63, 146-163.

Hogan, R. (1986). Hogan Personality Inventory manual. Minneapolis: National Computer Systems.

Hogan, R., \& Hogan, J. (1992). Hogan Personality Inventory manual. Tulsa, OK: Hogan Assessment Systems.

Jackson, D. N. (1984). Personality Research Form manual (3rd. ed.). Port Huron, MI: Research Psychologists Press.

John, O. P. (1989). Towards a taxonomy of personality descriptors. In D. M. Buss \& N. Cantor (Eds.), Personality psychology: Recent trends and emerging directions (pp. 261-271). New York: Springer-Verlag.

John, O. P., Hampson, S. E., \& Goldberg, L. R. (1991). The basic level in personality-trait hierarchies: Studies of trait use and accessibility in different contexts. Journal of Personality and Social Psychology, 60, 348-361.

Johnson, J. H., Butcher, J. N., Null, C., \& Johnson, K. N. (1984). Replicated item level factor analysis of the full MMPI. Journal of Personality and Social Psychology, 47, 105-114.

Johnson, J. A., \& Ostendorf, F. (1993). Clarification of the five-factor model with the abridged Big Five dimensional circumplex. Journal of Personality and Social Psychology, 65, 563576.

Leary, T. (1957). Interpersonal diagnosis of personality New York: Ronald Press.

McAdams, D. P. (1992). The five-factor model in personality: A critical appraisal. Journal of Personality; 60, 329-361.

McCrae, R. R. (1987). Creativity, divergent thinking, and openness to experience. Journal of Personality and Social Psychology, 52, 1258-1265.

McCrae, R. R. (1990). Traits and trait names: How well is Openness represented in natural languages? European Journal of Personality, 4, 119-129.

McCrae, R. R. (1991, August). The counterpoint of personality assessment: Self-reports and ratings. Invited address, Annual Convention of the American Psychological Association, San Francisco.

McCrae, R. R., \& Costa, P. T., Jr. (1985). Openness to experience. In R. Hogan \& W. H. Jones (Eds.), Perspectives in personality (Vol. 1, pp, 145-172). Greenwich, CT: JAI.

McCrae, R. R., \& Costa, P. T., Jr. (1989). The structure of interpersonal traits: Wiggins's circumplex and the five-factor model. Journal of Personality and Social Psychology, 56, 586-595

McCrae, R. R., \& Costa, P. T., Jr. (1992). Discriminant validity of NEO-PI-R facet scales. Educational and Psychological Measurement, 52, 229-237.

McCrae, R. R., \& Costa, P. T., Jr. (in press). Conceptions and correlates of Openness to Experience. In R. Hogan, J. A. Johnson, \& S. R. Briggs (Eds.), Handbook of personality psychology. New York: Academic.

McCrae, R. R., Costa, P. T., Jr., \& Busch, C. M. (1986). Evaluating comprehensiveness in personality systems: The California Q-Set and the five-factor model. Journal of Personality, $54,430-446$.

McCrae, R. R., Costa, P. T., Jr., \& Piedmont, R. L. (1993). Folk concepts, natural language, and psychological constructs: The Califomia Psychological Inventory and the five-factor model. Journal of Personality, 61, 1-26.

McCrae, R. R., \& John, O. P. (1992). An introduction to the five-factor model and its applications. Journal of Personality, 60, 175-215.

Mershon, B., \& Gorsuch, R. L. (1988). Number of factors in the personality sphere: Does increase in factors increase predictability of real-life criteria? Journal of Personality and Social Psychology, 55, 675-680. 
Miller, T. (1991). The psychotherapeutic utility of the five-factor model of personality: A clinician's experience. Journal of Personality Assessment, 57, 415-433.

Morris, W. (Ed.). (1976). The American heritage dictionary of the English language. Boston: Houghton Mifflin.

Mutén, E. (1991). Self-reports, spouse ratings, and psychophysiological assessment in a behavioral medicine program: An application of the five-factor model. Journal of Personality Assessment, 57, 449-464.

Paunonen, S. V., Jackson, D. N., Trzebinski, J., \& Forsterling, F. (1992). Personality structure across cultures: A multimethod evaluation. Journal of Personality and Social Psychology, 62, 447-456.

Shock, N. W., Greulich, R. C., Andres, R., Arenberg, D., Costa, P. T., Jr., Lakatta, E. G., \& Tobin, J. D. (1984). Normal human aging: The Baltimore Longitudinal Study of Aging (NIH Publication No. 84-2450). Bethesda, MD: National Institutes of Health.

Spielberger, C. D. (1972). Anxiety as an emotional state. In C. D. Spielberger (Ed.), Anxiety: Current trends in theory and research (Vol. 1, pp. 23-49). New York: Academic.

Trapnell, P. D., \& Wiggins, J. S. (1990). Extension of the Interpersonal Adjective Scales to include the Big Five dimensions of personality. Journal of Personality and Social Psychology, 59, 781-790.

Watson, D., \& Clark, L. A. (in press). Extraversion and its positive emotional core. In R. Hogan, J. A. Johnson, \& S. R. Briggs (Eds.), Handbook of personality psychology. New York: Academic.

Weber, M. (1930). The Protestant ethic and the spirit of capitalism. New York: Scribner. (Original work published 1904)

Wiggins, J. S. (1968). Personality structure. In P. R. Farnsworth, M. R. Rosenzweig, \& J. T. Polefka (Eds.), Annual Review of Psychalogy (Vol. 19, pp. 293-350). Palo Alto, CA: Annual Reviews.

Wiggins, J. S. (1979). A psychological taxonomy of trait-descriptive terms: The interpersonal domain. Journal of Personality and Sacial Psychology, 37, 395-412.

Wiggins, J. S. (1992). Have model, will travel. Journal of Personality, 60, 527-532.

Zuckerman, M., \& Lubin, B. (1965). The Multiple Affect Adjective Checklist. San Diego, CA: EdITS.

Paul T. Costa, Jr.

Laboratory of Personality and Cognition

Gerontology Research Center

National Institute on Aging, NIH

4940 Eastern Avenue

Baltimore, MD 21224

Received April 21, 1994

Revised June 23, 1995 